\title{
Metazoan community structure in relation to the fractal dimensions of marine macroalgae
}

\author{
J. M. Gee, R. M. Warwick \\ Plymouth Marine Laboratory, Prospect Place, The Hoe, Plymouth PL1 3DH, United Kingdom
}

\begin{abstract}
A measure of the complexity of a habitat independent of habitat type has long been required by benthic ecologists, particularly when comparisons between habitats or substrates need to be made and related to parameters of community structure. Using marine algae from the Isles of Scilly, UK, and their associated epifaunal communities as a testbed we have investigated how the use of fractals may be one method of solving some of these problems. The fractal dimensions of 4 species of macroalgae with a range of growth forms indicate an increasing order of complexity, which is paralleled by differences in the community composition and increasing diversity of 2 different size fractions of the epifaunal communities associated with each alga. We conclude that the fractal dimensions of the habitat provide a numerical expression of complexity which is easy to calculate, is independent of the nature of the habitat and is related to the scale at which the habitat may be viewed by the size hierarchies of animals which occupy it.
\end{abstract}

KEY WORDS: Fractals Habitat complexity - Macroalgae Macrofauna Meiofauna

\section{INTRODUCTION}

The concept that the structure of a community is related to the complexity of its habitat, first formulated by MacArthur \& MacArthur (1961), is now firmly established from a number of studies in terrestrial (MacArthur et al. 1966, Pianka 1969, Southwood et al. 1979, August 1983) and aquatic ecosystems (Heck \& Wetstone 1977, Hicks 1980, Stoner \& Lewis 1985). Complexity is concerned with the small-scale characteristics of a habitat such as the size, shape, surface texture and degree of angularity of a substrate and their relationship to inter-substrate spaces. It has generally been shown that increasing habitat complexity can be predicted to increase the diversity and abundance of organisms as a result of increased living space (Morse et al. 1985), increased variety of food organisms (Fretter \& Manley 1977) or suitable feeding surfaces, modification of microenvironmental conditions (Gibbons 1988a) and increased protection from predation (Coull \& Wells 1983, Gibbons 1988b).

The techniques for measuring complexity in marine habitats are varied and to some extent subjective. In soft sediments such measures as grain size and sedi- ment sorting coefficients (Gray 1974, Etter \& Grassle 1992), size of interstitial spaces (Williams 1971) or the percentage of the habitat or the biomass of aboveground or subterranean biogenic structures (Marinelli \& Coull 1987, Thistle et al. 1993) have been used. In phytal habitats, Warwick (1977) grouped algae by texture and feel and Edgar (1983) and Holmlund et al. (1990) by a subjective assessment of degree of branching. However, simple biomass or volume of algae has been the most commonly used complexity index (Heck \& Wetstone 1977, Coull et al. 1983, Stoner \& Lewis 1985, Hall \& Bell 1988) but this is generally unsuitable as it fails to take into account the varying mass of different algae. Alternatively the surface area of a known weight of algae has been used (Hicks 1977, 1980, Russo 1990) but again because of the varying mass of different algae this does not always adequately represent the order of complexity which might intuitively be expected in a range of algal growth forms (Gibbons 1988 b). So far the best measure of complexity appears to be one incorporating both surface area and volume into a ratio (Coull \& Wells 1983).

However, all these measures of complexity are unsatisfactory for a number of reasons. They give no indi- 
cation of the essential fine structure of substrates and prohibit any comparisons of complexity between different types of substrates (e.g. macroalgae and coral reefs). In addition, such measures have no mathematical basis on which predictions of the effects of habitat complexity on communities can be made. Further, they do not take into account the question of habitat scale and the way in which this is perceived by organisms of different size, which Hicks (1985) recognised as an important aspect of habitat complexity.

The advent of fractal geometry (concerned with the study of rugged lines/surfaces as opposed to Euclidean geometry which deals with the study of smooth surfaces) has opened up the possibilities of a formal definition of habitat complexity in terms of its fractal dimension. The concept of fractals (first introduced by Mandlebrot 1967, 1977) and its origins in measurement theory are explained by Kaye (1989) and its relevance to ecology reviewed by Sugihara \& May (1990). Briefly, Mandlebrot showed that many natural surfaces are fractal inasmuch as their length or area increases as the unit of measurement decreases. He illustrated this by discussing the problem of the length of the coastline of Britain. This can be approximated by enclosing a map of Britain in a polygon of $N$ straight line segments each with length $\lambda_{i}$ the overall length would be the number of sides multiplied by the length of a side. However, as smaller and smaller lengths are used for the sides of the polygon or the map of Britain is examined at finer scales, more and more of the twists and turns will be incorporated and the overall measure of length will increase. For many natural objects this increase in length $(L)$ occurs according to the simple power law:

$$
L(\lambda)=K \lambda^{i-D}
$$

where $K=$ a constant; and $D=$ the fractal dimension. For Euclidean geometry $D=1$ and the length is a constant independent of the scale of measurement. For fractal objects, boundary lengths become infinite as the scale of measurement tends towards zero although for real objects there will be a physical limitation to the minimum meaningful scale. However, it is more than just a question of measurement accuracy because a tree trunk, say, has a larger and larger circumference as one moves to smaller and smaller measurement scales, and this has consequences for the way it looks to animals of different sizes. In addition, if the tree trunk has a fractal dimension of say, 1.5 then an order of magnitude reduction in measurement scale will increase the apparent circumference by $10^{0.5}$ or a factor of 3

Further, a smooth surface/line has a fractal dimension of 1 and the fractal dimension increases as the ruggedness or complexity of the boundary increases.
Therefore, the fractal exponent cescribes the complexity of a shape or habitat which has relevance to the way in which animals living in it perceive that habitat. For some natural objects such as a fern leaf, the structure of the outline is an exactly self-repeating pattern on a smaller and smaller scale. For these objects, the fractal dimension will remain the same at whatever magnification the object is viewed. However, for most. natural objects with fractal characteristics, this selfrepeating pattern does not occur and the fractal dimension itself will change with changes in the measurement scale or magnification at which it is viewed. This may be illustrated by considering a ball of wool which, when viewed by a man, is a sphere with minor corrugations, whereas to a mouse it is a matrix of circular fibres and to a flea a forest of fibres on a curved surface.

Therefore, compared to the measures of complexity outlined above, fractals provide a numerical expression of complexity which is totally independent of the nature of the habitat and is related to the scale at which the habitat is viewed, i.e. is biologically meaningful in terms of the size hierarchies of animals occupying the habitat. In this study, therefore, we have calculated the fractal dimensions of small marine algae with a range of growth forms to determine the usefulness of fractals as a measure of complexity, and examined different size fractions (macrofauna and meiofauna) of the communities of metazoan animals inhabiting these algae to ascertain whether general measures of community structure can be related to habitat complexity.

\section{METHODS}

The area chosen for this study was the Isles of Scilly, UK (Fig. 1), a group of small islands 40 miles off Lands End in the extreme southwest of Britain. These islands are formed of hard granite, are surrounded by clear unpolluted water with a minimal silt content and are open to the full influence of the Atlantic Ocean. This hopefully minimized the effect of sediment accumulating on the algal fronds, which might affect their fractal dimensions and their faunal communities, although the increased accumulation of coarser-grained sediments in algae of increased complexity has not been entirely avoided.

In April 1987, 8 sites (numbered as in Fig. 1) were sampled on 3 islands with at least 1 site on the more exposed and more sheltered side of each island. At each site as many as possible of 7 different species of small macroalgae were collected off rocks between mean low water and low water of spring tides. Enough of each algal species was carefully picked off exposed 


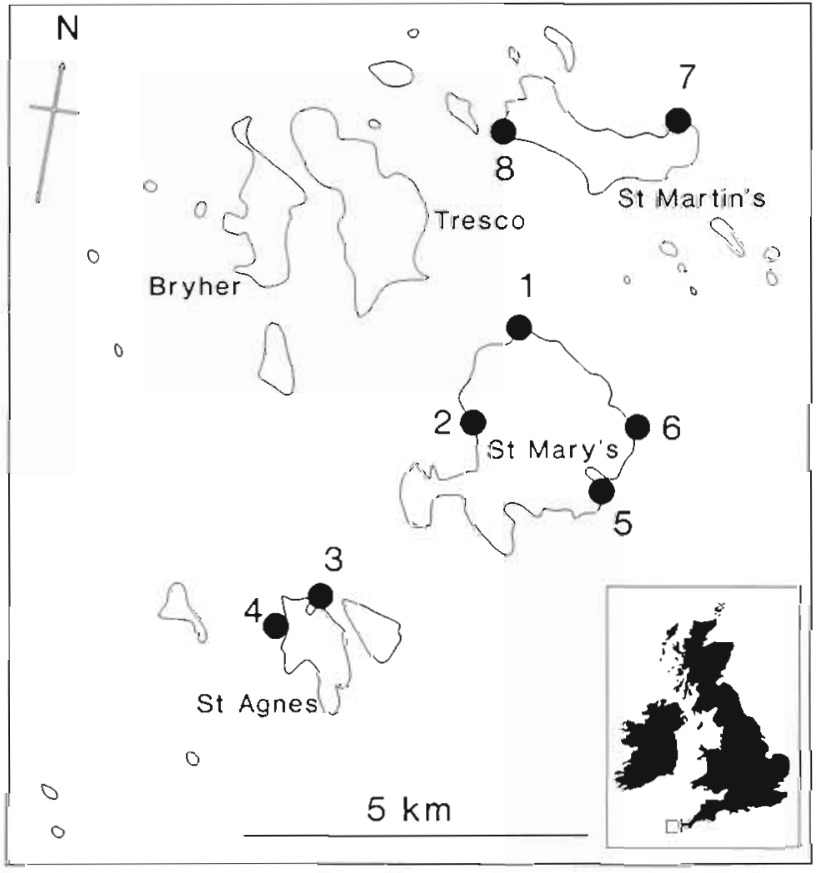

Fig. 1. Sampling stations on the Isles of Scilly

rocks along the shore so as to fill a 0.51 collecting pot containing $10 \%$ formalin. This quantity was judged to be sufficient to characterize adequately the communities of each alga but undoubtedly the volume, surface area or weight of the different algae collected was not the same. In the laboratory the fronds from each algal sample were washed in a bucket of fresh water and the fauna passed through a $0.5 \mathrm{~mm}$ sieve to retain macrofauna and a $0.063 \mathrm{~mm}$ sieve to retain meiofauna. These 2 fractions were preserved separately in $4 \%$ formalin for later analysis. A random sample of fronds of each algal species was also preserved in formalin for later determination of fractal dimensions.

On completion of sampling it was found that only 4 species of macroalgae were common to all lowwater sites, Chondrus crispus (L.), Laurencia pinnatifida (Hudson), Lomentaria articulata (Hudson) and Cladophora rupestris (L.) (hereafter referred to by generic names only)

The fractal dimensions of each of these 4 algae were determined by the dividers method described in Kaye (1989) and Sugihara \& May (1990). A frond or portion of frond approximately $30 \mathrm{~mm}$ in length was mounted between glass slides under a binocular dissecting microscope fitted with a camera lucida. An accurate drawing of the outline of the frond was then made (Fig. 2) at 2 magnifications $(6 \times$ and $12 \times$ for Chondrus and Laurencia, $12 \times$ and $24 \times$ for Lomentaria and $28 \times$ and $56 \times$ for Cladophora). The perimeter length was measured with a pair of dividers by starting at one point and swinging

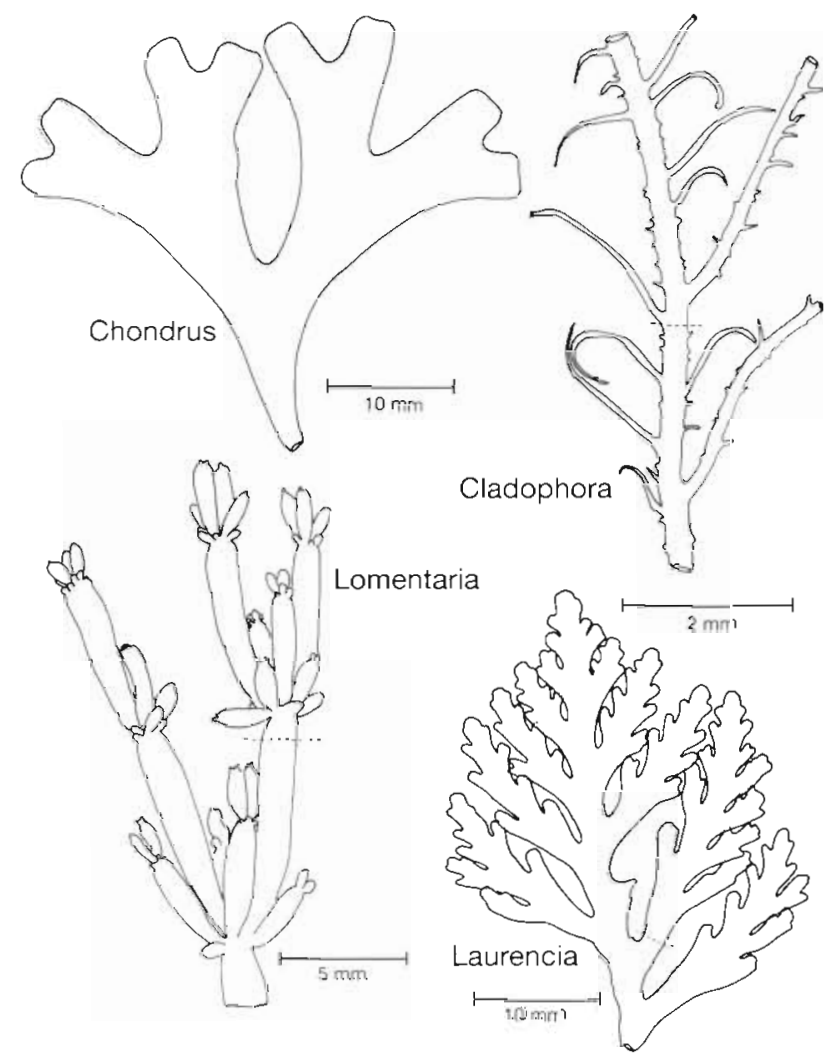

Fig. 2. Chondrus crispus, Laurencia pinnatifida, Lomentaria articulata and Cladophora rupestris. Outlines of the 4 species of algae at the lowest magnification at which the fractal dimensions were estimated. Dashed line delimits the portion of the frond used to estimate the fractal dimensions at the higher magnification

the dividers (either outswing or inswing; Kaye 1989) to the nearest next point on the border. The process was repeated in a clockwise and anticlockwise direction and from each of 6 randomly chosen starting points for a range of step sizes calculated as a proportion of the overall size of the image (Feret distance). Expressing step size $(\lambda)$ in this way means that objects of differing size could be compared. The mean and 2 SDs of perimeter length were then plotted ( $y$-axis) against proportional step size ( $x$-axis) on $\log$ scales in a Richardson plot (Fig. 3) and the fractal dimension $(D)$ found from the slope of the regression line $([\mathrm{m}])$ by $D=$ $1+[m]$.

In the macrofauna fraction from the 4 algae, the animals (principally polchaetes, amphipods, isopods, tanaids and molluscs) were hand picked-from the whole sample, counted and identified to the lowest taxon possible. For the meiofauna the contents of the whole sample were elutriated 6 times in a $1 \mathrm{l}$ measuring cylinder, and all the copepods picked out, counted and identified to species. One-tenth subsamples of the remainder of the sample were transferred to 
pure glycerine by slow evaporation (Riemann 1988), mounted in glycerine and the cover slip ringed with Bioseal. The remaining meiofaunal hard-bodied groups (nematodes, ostracods and halicarid mites) were then counted and identified to species or putative species and the numbers subsequently adjusted to whole sample size.

A number of univariate, graphical/distributional and multivariate methods were employed in the analysis of the biological data set. Indices of species richness (Margalef's $d$ ), Shannon-Wiener diversity $\left(H^{\prime}\right)$ and evenness (Pielou's $J$ ) using logarithms to base e were calculated and the significance of the difference between macroalgae was tested by 1 -way ANOVA. $k$-dominance curves were constructed after Lambshead et al. (1983) and tests for the significance of differences between replicated curves for each macroalga followed the methods of Clarke (1990). The multivariate method employed was nonmetric multidimensional scaling ordination (MDS) using the Bray-Curtis similarity measure for standardized, double square-root transformed species abundance data. Significance and sources of differences between macroalgae were tested using the methods [analysis of similarity (ANOSIM) and similarity percentages procedure (SIMPER)] described in Clarke (1993) and contained in the Plymouth Routines In Multivariate Ecological Research (PRIMER) computer package produced by Plymouth Marine Laboratory.

\section{RESULTS}

\section{Complexity of algae}

Fig. 2 shows the outlines of the 4 species of algae at the lowest magnification (see 'Methods') at which the fractal dimension was estimated. Chondrus crispus (Rhodophyta) is a cartilaginous plant growing individually or in loose clusters with a narrow base expanding into a flat dichotomously branched thallus. Laurencia pinnatifida (Rhodophyta) is also a cartilaginous plant growing in denser clusters than the previous species, but again with a flat thallus alternately branching in a more or less self-repeating formation. Lomentaria articulata (Rhodophyta) is a small, gregarious, tufted, 3-dimensional plant with a hollow thallus, constricted at regular intervals, from which issues a circlet of branches in a self-repeating pattern. Cladophora rupestris (Chlorophyta) consists of monosiphonous filaments growing in dense tufts from a rhizoidal base, with each filament profusely and irregularly branched (Dickinson 1963)

Fig. 3 is a Richardson plot for Laurencia which shows that at large values of $\lambda$, the variance of perimeter length is high, so the regression equations have been

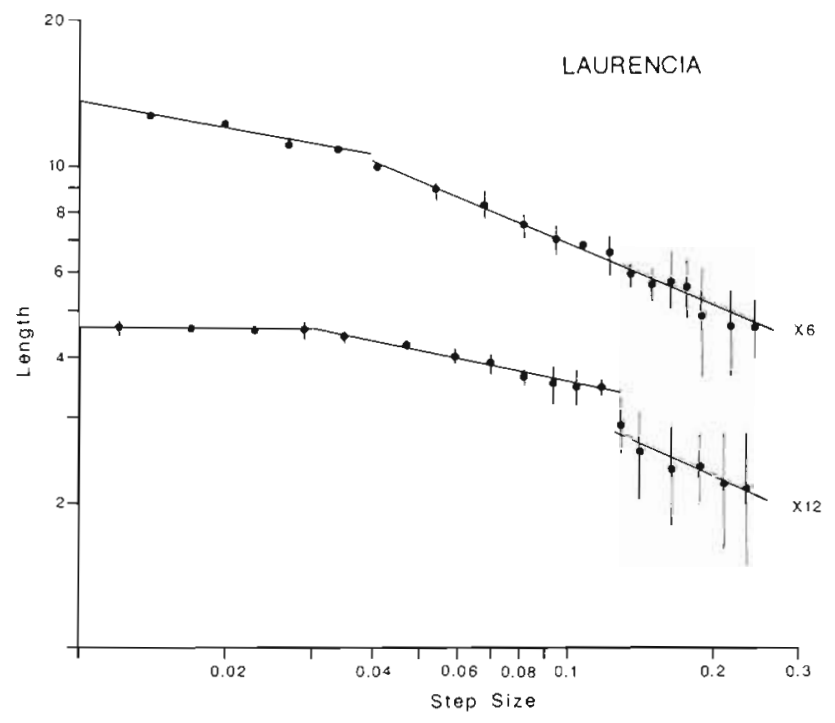

Fig. 3. Laurencia pinnatifida. Richardson plot of perimeter length against step size at 2 magnifications $(6 \times, 12 \times)$. Error bars: 2 SD

calculated excluding perimeter values above a $\lambda$ of 0.2 . Further, from a visual examination of the points at each magnification it is clear that the best fit is not obtained from a single regression line. Multiple regression lines were therefore fitted to the series of points which gave the highest correlation coefficient ( $\mathrm{r}$ ). At $6 \times$ magnification Laurencia has a fractal dimension $(D)$ of $1.43(\mathrm{r}=$ -0.99 ) for a $\lambda$ range of 0.04 to 0.25 (normalised with respect to the maximum Feret distance). However, below $\lambda$ of 0.04 , Laurencia shows a different fractal dimension of $1.19(r=-0.97)$. These values are interpreted as reflecting 2 aspects of the configuration of the alga (Kaye 1989): the first, the overall structure of the shape (termed the structural fractal, $D_{\mathrm{s}}$ ), and the second the detailed texture of the surface (the textural fractal, $D_{\mathrm{t}}$ ). At $12 \times$ magnification a similar $D_{\mathrm{s}}$ of 1.45 (r $=-0.93$ ) is indicated for $\lambda$ of 0.13 to 0.25 and a $D_{t}$ of 1.22 $(\mathrm{r}=-0.99)$ for $\lambda$ of 0.03 to 0.12 , although the $D_{\mathrm{s}}$ at this magnification may be false because of the very elliptical nature of the shape isee portion delimited by a dashed line in Fig. 2). However, at $12 \times$ magnification for $\lambda$ of $<0.03$ the slope of the regression line is almost zero, $D=1.02(\mathrm{r}=-0.88)$ and the shape becomes Euclidian in that there is no increase in perimeter length for further reductions in step size. If the step size units are converted to actual lengths relative to the true size of the aiga and equated with some measure of body size of the inhabiting animals it can be deduced that, for animals, over approximately $2 \mathrm{~mm}$ in size (i.e. the macrofaunal component of the community), the fractal dimension of Laurencia is 1.43 and therefore for an order of magnitude decrease in body size the per- 
ceived habitat size will increase by a factor of 2.7 $\left(10^{0.43}\right)$. For animals in the size range of 0.6 to $2.0 \mathrm{~mm}$ (covering most of the meiofaunal component of the community) the complexity of the alga is much reduced ( $D=1.19$ ) and for animals below $0.6 \mathrm{~mm} \mathrm{Lau-}$ rencia has no discernable structure and presents a more or less smooth surface.

Table 1 gives the fractal dimensions of the 4 species of algae examined for the range of step sizes which correspond to animal body sizes of $>2,0.5$ to 2.0 and $<0.5 \mathrm{~mm}$. In the macrofaunal size range, Chondrus $\left(D_{\mathrm{s}}\right.$ $=1.22)$ is the least complex alga followed by Lomentaria $\left(D_{\mathrm{s}}=1.33\right)$, whilst Laurencia $\left(D_{\mathrm{s}}=1.43\right)$ is the most complex. Cladophora has a thallus which is too small and fine to determine a fractal dimension at a scale which can be equated with this body size of animal. For the range of values of $\lambda$ which can be equated with meiofaunal body size, Chondrus ( $D=1.0)$ has no complexity but is perceived as a smooth surface, and Laurencia $\left(D_{1}=1.22\right)$ is slightly less complex than Lomentaria $\left(D_{\mathrm{t}}=1.29\right)$ but both are significantly less complex than Cladophora $\left(D_{\mathrm{s}}=1.59\right)$.

\section{Epifaunal communities of algae}

In all, 253 taxa were identified, 158 meiofaunal species and 95 macrofaunal species.

\section{Multivariate measures}

Sample sites (Fig. 1) were located on the exposed (Sites 4, 5, 6, 7) and sheltered (Sites 1, 2, 3, 8) sides of 3 islands. Preliminary ordinations of the samples by sites (Fig. 4) indicates that the communities are not significantly different, and this is confirmed by ANOSIM with a sample statistic of 0.045 for meiofauna and 0.061 for macrofauna and sites not significantly different at the $5 \%$ level. The epifaunal communities of algae

Table 1. Chondrus crispus, Laurencia pinnatifida, Lomentaria articulata and Cladophora rupestris. Fractal dimensions $(D)$ of 4 species of macroalgae examined at various magnifications (A: $6 x ; B: 12 \times ; C: 24-28 \times ; D: 56 \times$ ) for a range of $\lambda$ equated with 3 body-size categories of epifauna. Confidence intervals cannot be quoted as only 1 frond of each species was used to estimate fractal dimensions

\begin{tabular}{|lccc|}
\hline Algae & \multicolumn{3}{c|}{ Body size (mm) } \\
& $>2$ & $0.5-2.0$ & $<0.5$ \\
\hline Chondrus sp. & $1.22(\mathrm{~A})$ & $1.00(\mathrm{~A})$ & $1.00(\mathrm{~A})$ \\
Laurencia sp. & $1.43(\mathrm{~A})$ & $1.22(\mathrm{~B})$ & $1.00(\mathrm{~B})$ \\
Lomentaria sp. & $1.33(\mathrm{~B})$ & $1.29(\mathrm{C})$ & $1.09(\mathrm{C})$ \\
Cladophora sp. & - & $1.59(\mathrm{C})$ & $1.29(\mathrm{D})$ \\
\hline
\end{tabular}

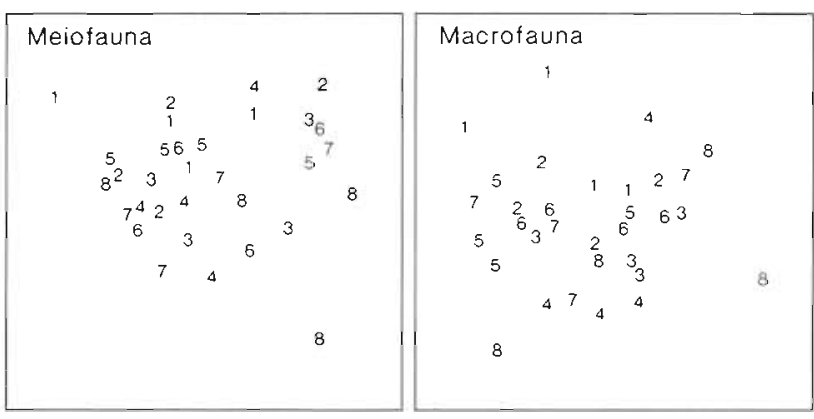

Fig. 4. MDS ordination (using Bray-Curtis similarity measure) of macrofauna and meiofauna communities on all algae at Sites 1 to 8

were therefore unaffected by locality, and samples from the 8 sites could be used as 8 valid replicates of algal type.

Ordinations of the communities by algal type (Fig. 5) show a distinct clustering, particularly for the meiofauna where the community on Chondrus cluster on the left of the plot followed in order by Laurencia, Lomentaria to Cladophora on the right of the plot. Both the relative spacing and the ordering of the communities are comparable to the value differences and order of increasing habitat complexity as deduced from the fractal dimension in the range of $\lambda$ values equivalent to animal body sizes in the 0.5 to $2.0 \mathrm{~mm}$ range (Table 1 ). The ordination of macrofauna communities is less distinct than for the meiofauna, nevertheless Chondrus communities cluster at the left followed by Lomentaria, Laurencia to Cladophora on the right. This is the same as the order of increasing habitat complexity as deduced from the fractal dimensions in the range of $\lambda$ values equivalent to animal body sizes of $>2 \mathrm{~mm}$, where Laurencia has a higher fractal dimension than Lomentaria. The ANOSIM of algal effects suggests that the meiofauna, with a sample statistic $(S)$ of 0.53 , are slightly more responsive to changes in thallus

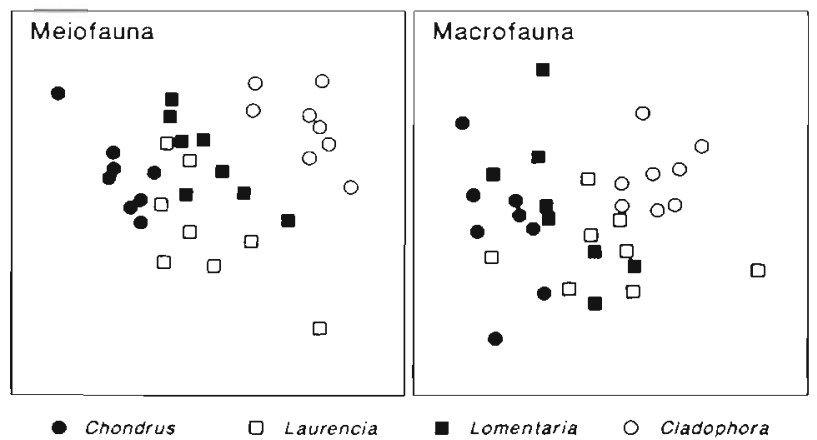

Fig. 5. Chondrus crispus, Laurencia pinnatifida, Lomentaria articulata and Cladophora rupestris. MDS ordination of macrofauna and meiofauna communities on 4 species of macroalgae. (Stress values 0.19 and 0.18 respectively) 
structure than the macrofauna, whose sample statistic $(S)$ is 0.47 , but in both cases these are significant at the $0.1 \%$ level. In the pair-wise comparisons all differences between algal communities are significant at the $1 \%$ level, except between Laurencia and Lomentaria (significance level 1.9\%) for the meiofauna and between Chondrus and Lomentaria (significance level $3.2 \%$ ) for the macrofauna.

The meiofauna community is dominated by copepods (72 species) and nematodes (59 species). In their general body shape and external morphology almost all nematode species are very similar and not particularly adapted for phytal habitats, except for the Draconematidae which were rare in these samples. Copepods, on the other hand, have a variety of body forms and a range of structurally different appendages and many genera and some families are found predominantly in phytal habitats. It might be expected, therefore, that the copepods would be more responsive to variations in substrate structure in phytal habitats. The ordinations in Fig. 6 show that this is the case, with the distinction between algal assemblages being more obvious for copepods ( $S=0.45$ and all algae are significantly different at the $1 \%$ level) than for nematodes where $S=0.33$ and the differences among Chondrus, Laurencia and Lomentaria are not significant at the $5 \%$ level.

SIMPER analysis (which produces tables, too large to be included here, of percentage contribution of each epifaunal species to differences between communities on each pair of macroalgae) indicates that the differences between algae in community structure of both macrofauna and meiofauna are not merely changes in dominance of the most abundant species but are the result of subtle changes in the abundance of a large number of species. Within the harpacticoid copepods there are some obvious differences in composition between algae. Harpacticoids with a broad, strongly dorso-ventrally flattened body form and mouthparts or

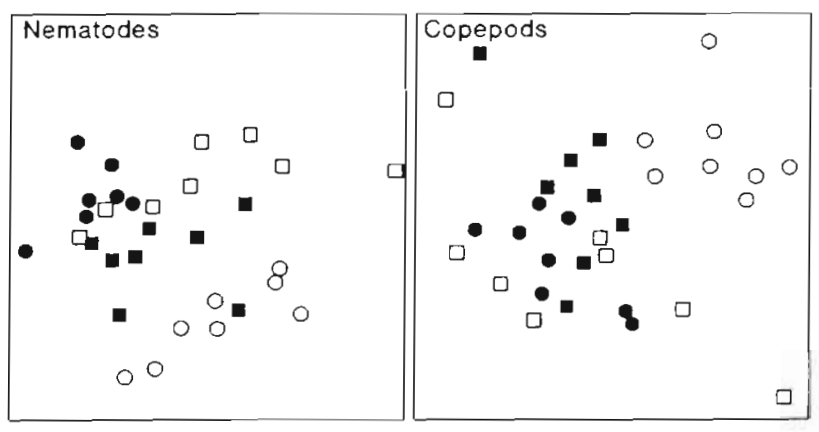

Fig. 6. Chondrus crispus, Laurencia pinnatifida, Lomentaria articulata and Cladophora rupestris. MDS ordination of copepods and nematode communities on 4 species of macroalgae (stress values 0.2 and 0.21 respectively). Key as in Fig. 5 body segments often adapted for suction adhesion (e.g. Zaus spp., Saccodiscus spp., Scutellidium spp., Alteutha spp., Porcellidium spp.) are either only present or more abundant on the more robust algae such as Chondrus and Laurencia, whereas harpacticoids with a narrow, elongate body form and maxillipeds and first legs adapted for clinging (e.g. most Laophontidae, Thalestridae, Parastenhelia spp. and Amphiascus spp.) are most abundant on Lomentaria and Cladophora.

\section{Univariate measures}

Univariate measures of community structure tend to be somewhat less sensitive than multivariate measures in distinguishing between communities because they do not take into account the identity of the species involved (Warwick \& Clarke 1991). However they do express the distribution of individuals amongst species in a numerical form which may be related more directly to the fractal dimensions of the substrate.

The mean and $95 \%$ confidence intervals of total individuals, total species, Margalef species richness index, Shannon-Wiener diversity index and the Pielou evenness index for macrofauna and meiofauna are shown in Figs. 7 \& 8. For each size fraction of the community all measures of diversity were correlated with the order of algal complexity relevant to that size fraction (i.e. reflected the switching of complexity order between Laurencia and Lomentaria for macrofauna and meiofauna). However, for both macrofauna and meiofauna, differences between algae were significant at the $0.1 \%$ level only for abundance, total species and Margalef's $d$

The distribution of individuals among species can also be expressed graphically in $k$-dominance curves but in this case these were not particularly useful as they did not distinguish between communities (except to show that the copepod assemblages on Cladophora are distinct from the other algae) and are not presented here

\section{DISCUSSION}

Hicks (1980) and Gibbons (1988a) showed that the composition of the harpacticoid copepod communities of a range of macroalgae was significantly different and in some respects could be related to the complexity of the algae as estimated by the surface area per gram dry weight of the alga, although this measure did not always place the algae in an order of complexity which might intuitively be expected from a visual examination of the weeds and the diversity of their 
MACROFAUNA
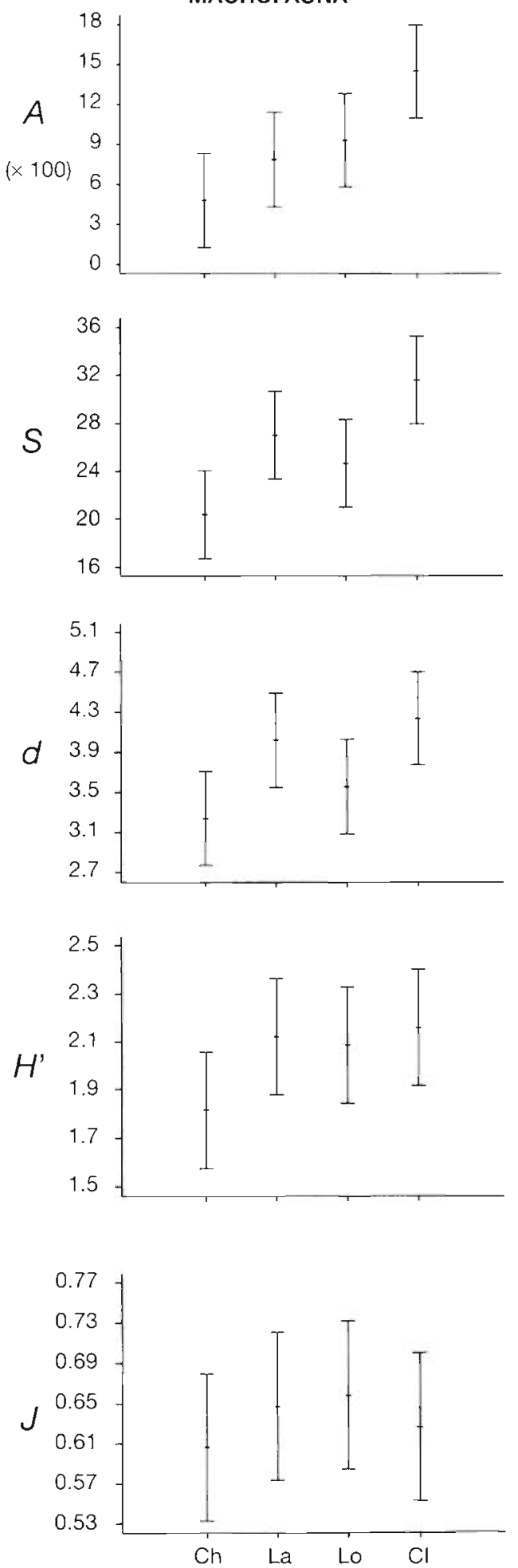

Fig. 7. Chondrus crispus, Laurencia pinnatifida, Lomentaria articulata and Cladophora rupestris. Mean and $95 \%$ confidence intervals of univariate measures of community structure for macrofauna on 4 species of algae $(\mathrm{Ch}=$ Chondrus; $\mathrm{La}=$ Laurencia; Lo = Lomentaria; $\mathrm{Cl}=$ Cladophora). A: abundance; $S$ : number of species; $d$ : Margelef's species richness index; $H^{\prime}$ : Shannon Wiener diversity index; J: Pielou's evenness index
MEIOFAUNA
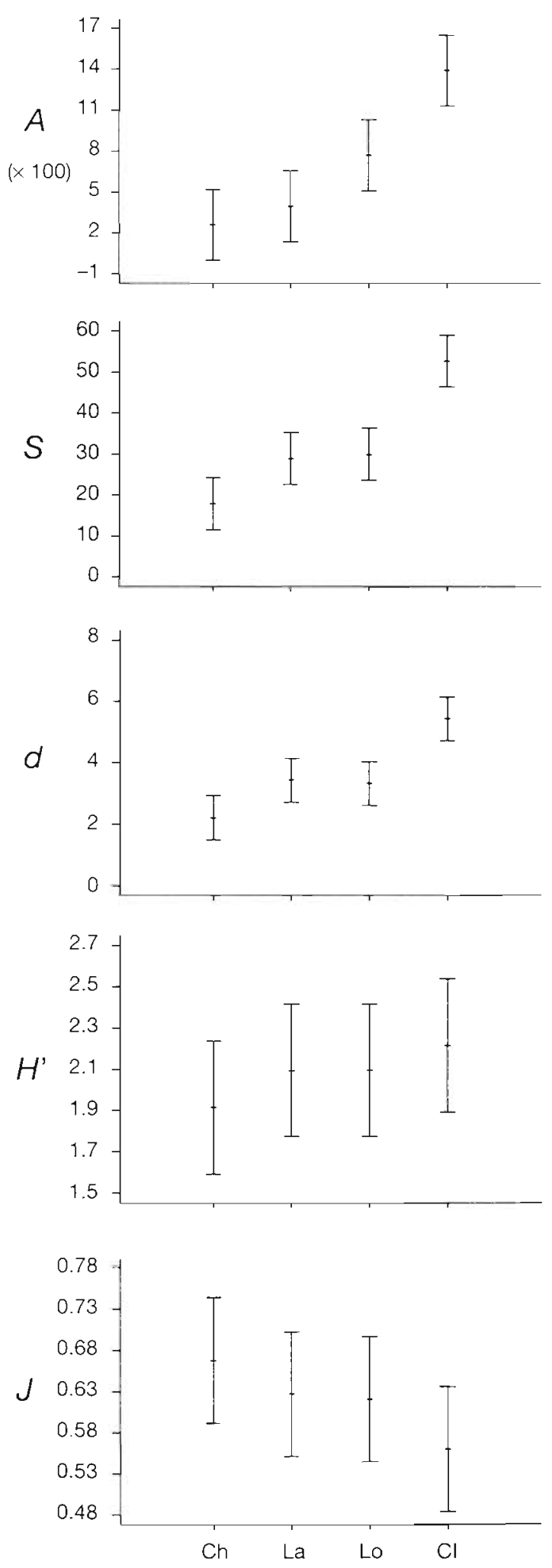

Fig. 8. Chondrus crispus, Laurencia pinnatifida, Lomentaria articulata and Cladophora rupestris. Mean and $95 \%$ confidence intervals of univariate measures of community structure for meiofauna on 4 species of algae (symbols as in Fig. 7) 
epifauna (Gibbons 1988b) On the other hand, Russo (1990) found that the complexity of marine algae as measured by the ratio of surface area to biomass was not a consistent predictor of the abundance and diversity of amphipod communities. Whilst there may be many explanations for these observations, an obvious one is that the measures used do not adequately represent habitat complexity in the first place. They are not independent of the mass of the substrate (algae) which has no relation to the notion of complexity and although the surface area of some 2-dimensional algae can be fairly accurately determined by a graphical method (Johnson \& Scheibling 1987), we have found that the 'Teepol' method of Harrod \& Hall (1962), widely used for estimating the surface area of more complex algae, is very unreliable.

Fractal dimensions overcome these problems because they are a mathematical expression of the degree of ruggedness of the shape of a substrate, which is totally independent of the nature of that sub. strate. Thus not only do they provide a better measure of within-habitat (e.g. macroalgae) complexity but also allow potential comparisons of complexity between totally different habitats such as coral reefs (Bradbury et al. 1984), trees (Morse et al. 1985), lichens (Shorrocks et al. 1991) and organic and inorganic particles (Kaye 1989; Logan \& Wilkinson 1990). For instance, soft sediment is the other major marine habitat of meiofauna but comparisons of the community structuring function of complexity in macroalgae and sediments cannot at present be made because grain size and sorting coefficient are the measures of complexity used in soft sediments and in no way can these be related to the measures of complexity previously used for algae. Further, Marcotte (1986) (see also Hicks \& Coull 1983. p. 155-156) has shown with respect to food resource partitioning by harpacticoid copepods that the actual shape of sediment particles (angles, shear planes, pits and ridges) is of greater significance than grain size. Therefore using the fractal dimensions of the sediment particles may be a more meaningful way of defining sediment complexity which will not only allow direct comparisons of complexity between habitats or ecosystems, but may also allow greater generalizations with respect to the mechanisms by which habitat complexity structures benthic communities.

Another advantage of using fractal dimensions over other measures of complexity is that they incorporate the concept of habitat scale. We have demonstrated here (Fig. 3, Table 1) that the complexity of a habitat as defined by its fractal dimension is not necessarily constant but may change with the magnification or scale of measurement at which it is viewed. As stated earlier, if the measurement scale (step size) is equated with some measure of animal body size, the implications are that the same seaweed may have one level of complexity in relation to e.g. large amphipods (macrofauna) and quite a different level of complexity for small harpacticoid copepods (meiofauna).

The analyses of the faunal communities of the 4 species of algae used in this study appear to correlate with the fractal dimensions of the algae, both in the multivariate ordinations where the communities are arranged across the ordination in the order of increasing algal complexity, and in the univariate analyses where indices of diversity, particularly species richness, increase with increasing substrate complexity. The results also show that the changes in complexity at different measurement scales are reflected in differing responses of the 2 size fractions of the fauna. At the large measurement scales, Laurencia is more complex than Lomentaria while the opposite is the case at smaller measurement scales and these differences are reflected in both the multivariate and univariate analyses of the macrofauna and meiofauna size fractions of the community. Simlarly Chondrus has a higher fractal dimension at large measurement scales than at small measurement scales and the index of species richness on this alga is much higher for the macrofauna than for the meiofauna.

Thus fractal dimensions have many advantages over previous methods for the definition of habitat complexity in marine ecosystems. In addition, the boundary dimensions method used here for estimating the fractal dimension is relatively simple to calculate accurately although somewhat time consuming, particularly for the more complex algae. However, it would appear from this work that the number of estimations of boundary length at small step sizes can be reduced from 12 to 3 or 4 as the variance of the estimates is much reduced at small, compared to large, step sizes. With reference to the 4 algae examined here, it is suggested that the boundary dimension method of calculating the fractal dimension gives the best estimate of complexity for algae where the perimeter length is large relative to surface areas as in Cladophora with a narrow randomly branching thallus. Lomentaria has a similar thallus structure but this alga is highly 3 dimensional, with whorls of branches at regular intervals up the thallus, and estimation of fractals from the 2-dimensional representation of this algae (Fig. 2) may not adequately reflect its true complexity. Conversely, for broad flat highly 2-dimensional algae such as Chondrus where the perimeter length is small compared to the surface area of the thallus, the boundary dimension method of calculating the fractal may overestimate the complexity with respect to the habitable space occupied by the fauna.

For the characterization of complexity by fractal dimensions, 2 further points need to be considered in 
future. The first is the range of fractal values that might be obtained for each species of alga. Here we have estimated the fractal of only 1 thallus, chosen at random to be representative of the species. However, Shorrocks et al. (1991) estimated the fractal dimensions of a cross section of 8 thalli of the lichen Parmelia saxatilis and found the value of $D$ to range from 1.38 to 1.74 (mean 1.58, SE 0.04). If such a range of variation is found among algae then there is probably no significant difference between the complexity of Laurencia and Lomentaria over the range of step sizes equivalent to the 0.5 to $2.0 \mathrm{~mm}$ body size (a fact suggested by the faunal analysis).

A second point is that the complexity as expressed by the fractals of individual thalli takes no account of the packing density and size of inter-thallus spaces of the algae which is probably an important aspect of complexity from the point of view of the inhabiting fauna. Chondrus and Laurencia grow in loose clumps with wide inter-thallus spaces but Lomentaria and particularly Cladophora form dense tufts with much smaller inter-thallus spaces. It may be, therefore, that estimating the fractal dimensions from cross sections of the natural growth forms of these algae gives a better estimate of complexity than the measurement of boundary lengths of single thalli employed here. Further, if such random sections through the 3-dimensional habitat can be obtained, it may be that the application of recent advances in geometric probability and stereology for estimating available surface area at different scales provides a viable alternative to perimeter-based fractal dimensions for estimating the complexity of phytal and sedimentary habitats by benthic ecologists.

Acknowledgements. The authors thank members of the Community Ecology Project of the Plymouth Marine Laboratory for their contributions to the field work and for identification of some of the major faunal groups, in particular molluscs (J. T. Davey), polychaetes (C. George and M. A. Kendall), isopods and tanaids (Mrs A. McEvoy) and Mark Costello for checking the identifications of amphipods. In addition we thank K. R. Clarke for advice on the concept of fractal dimensions and (along with an unknown referee) for criticism of earlier drafts of the manuscript.

\section{LITERATURE CITED}

August, P. V (1983). The role of habitat complexity and heterogeneity in structuring tropical mammal communities. Ecology 64: 1495-1507

Bradbury, R. H., Reichelt, R. E., Green, D. G. (1984). Fractals in ecology: methods and interpretation. Mar Ecol. Prog. Ser. 14: 295-296

Clarke, K. R. (1990). Comparison of dominance curves. J. exp. mar. Biol. Ecol. 138: 143-157

Clarke, K. R. (1993). Non-parametric multivariate analyses of changes in community structure. Austr. J. Ecol. 18: 117-143
Coull, B. C., Creed, E. L., Eskin, R. A., Montagna, P. A., Palmer, M. A., Wells, J B. J. (1983). Phytal meiofauna from the rocky intertidal at Murrells Inlet, South Carolina. Trans. Am. microsc. Soc. 102: 380-389

Coull, B. C., Wells, J. B. J. (1983). Refuges from fish predation: experiments with phytal meiofauna from the New Zealand rocky intertidal. Ecology 64: 1599-1609

Dickinson, C. I. (1963). British seaweeds. Eyre \& Spottiswoode, London

Edgar, G. J (1983). The ecology of south-east Tasmanian phytal animal communities. IV Factors affecting the distribution of amphitoid amphipods among aigae. J. exp. mar. Biol. Ecol. 70: 205-225

Etter, R. J., Grassle, J. F. (1992). Patterns of species diversity in the deep sea as a function of sediment particle size diversity. Nature 360: 576-578

Fretter, V., Manley, R. (1977). Algal associations of Tricolia pullus, Lacuna vincta and Cerithiopsis tubercularis (Gastropoda) with special reference to the settlement of their larvae. J. mar. biol. Ass. U.K. 57: 999-1017

Gibbons, M. J. (1988a). The impact of sediment accumulation, relative habitat complexity and elevation on rocky shore meiofauna. J. exp. mar. Biol. Ecol. 122: 225-241

Gibbons, M. J. (1988b). Impact of predation by juvenile Clinus superciliosus on phytal meiofauna: are fish important as predators? Mar. Ecol. Prog. Ser. 45: 13-22

Gray, J. S. (1974). Animal-sediment relationships. Oceanogr mar. Biol. A. Rev. 12: 223-261

Hall, M. O., Bell, S. S. (1988). Response of small motile epifauna to complexity of epiphytic algae on seagrass blades. J. mar. Res. 46: 613-630

Harrod, J. J., Hall, R. E. (1962). A method of determining the surface areas of various aquatic plants. Hydrobiologia 20 : $173-178$

Heck, K. L., Wetstone, G. S. (1977). Habitat complexity and invertebrate species richness and abundance in tropical seagrass meadows. J. Biogeogr. 4: 135-142

Hicks, G. R. (1977). Species composition and zoogeography of marine phytal harpacticoid copepods from Cook Strait, and their contribution to total phytal meiofauna. N.Z. J. mar. Freshwat. Res. 11:441-469

Hicks, G. R. (1980). Structure of phytal harpacticoid copepod assemblages and the influence of habitat complexity and turbidity. J. exp mar. Biol. Ecol. 44: 157-192

Hicks, G. R. (1985). Meiofauna associationed with rocky shore algae. In: Moore, P. G., Seed, R. (eds.) The ecology of rocky coasts. Hodder \& Stoughton, London

Hicks, G. R., Coull, B. C. (1983). The ecology of marine meiobenthic harpacticoid copepods. Oceanogr mar. Biol. A. Rev. 21: 67-175

Holmlund, M. B., Peterson, C. H., Hay, M. E. (1990). Does algal morphology affect amphipod susceptibility to fish predation? J. exp. mar. Biol. Ecol. 139: 65-83

Johnson, S. C., Scheibling, R. E. (1987). Structure and dynamics of epifaunal assemblages on intertidal macroalgae Ascophyllum nodosum and Fucus vesiculosus in Nova Scotia, Canada. Mar Ecol. Prog. Ser. 37: $209-227$

Kaye, B. H. (1989). A random walk through fractal dimensions. VCH Publishers, Weinheim

Lambshead, P. J D., Platt, H. M., Shaw, K. M. (1983). The detection of differences among assemblages of marine benthic species based on an assessment of dominance and diversity. J. nat. Hist. 17: 859-874

Logan, B. E., Wilkinson, D. B. (1990). Fractal geometry of marine snow and other biological aggregates. Limnol. Oceanogr. 35: 130-136 
MacArthur, R. A., MacArthur, J. W. (1961). On bird species diversity. Ecology 42: 594-598

MacArthur, R. H., Recher, H., Cody, M. L. (1966). On the relation between habitat selection and species diversity. Am. Nat. 100: 319-332

Mandlebrot, B. B. (1967). How long is the coastline of Britain? Statistical self similarity and fractal dimension. Science 156: $636-638$

Mandlebrot, B. B. (1977). Fractals: form, chance and dimension. W. H. Freeman \& Co., San Francisco

Marcotte, B. M. (1986). Sedimentary particle sizes and the ecological grain of food resources for meiobenthic copepods. Estuar. coast. Shelf Sci. 23: 423-427

Marinelli, R. L., Coull, B. C. (1987). Structural complexity and juvenile fish predation on meiobenthos: an experimental approach. J. exp. mar. Biol. Ecol. 108: 67-81

Morse, D. R., Lawton, J. H., Dodson, M. M., Williamson, M. H. (1985) Fractal dimension of vegetation and the distribution of arthropod body length. Nature 314: 731-733

Pianka, E. R. (1969). Habitat specificity, speciation and species density in Australian desert lizards. Ecology 50: $498-502$

Riemann, F. (1988). Nematoda. In: Higgins, R. P., Thiel, H. (eds.) An introduction to the study of meiofauna. Smithsonian Institution Press, Washington, DC, p. 293-299

Russo, A. R. (1990). The role of seaweed complexity in structuring Hawaiian epiphytal amphipod communities. Hydrobiologia $94: 1-12$

This article was submitted to the editor
Shorrocks, B., Marsters, J., Ward, I., Evennett, P. J. (1991) The fractal dimensions of lichens and the distribution of arthropod body lengths. Func. Ecol. 5: 457-460

Southwood, T R. E., Brown, V. K., Reader, P. M. (1979). The relationship of plant and insect diversities in succession. Biol. J. Linn. Soc. 12: 327-348

Stoner, A. W., Lewis, F. G. III (1985). The influence of quantitative and qualitative aspects of habitat complexity in tropical seagrass meadows. J. exp. mar. Biol. Ecol. 94: 19-40

Sugihara, G. May, R. M. (1990). Applications of fractals in ecology. Trends Ecol. Evol. 3: 79-86

Thistle, D., Hilbig, B., Eckman, J. E. (1993). Are polychaetes sources of habitat heterogeneity for harpacticoid copepods in the deep sea? Deep Sea Res. I 40: 151-157

Warwick, R. M. (1977). The structure and seasonal fluctuation of phytal marine nematode associations on the Isles of Scilly. In: Keegan, B. F., Ceidigh, P. O, Boaden, P. J. S. (eds.) Biology of benthic organisms, 11th European Symposium on Marine Biology, Galway, October 1976. Pergamon Press, Oxford, p. 577-585

Warwick, R. M., Clarke, K. R. (1991). A comparison of some methods for analysing changes in benthic community structure. J. mar. biol. Ass. U. K. 71: 225-244

Williams, R. (1971). A technique for measuring the interstitial voids of a sediment based on epoxy resin impregnation. In: Hulings, N. C. (ed.) Proceedings of the First International Conference on Meiofauna, Smithson. Contr. Zool. 76: $199-205$

Manuscript first received: July 26,1993

Revised version accepted: October 12, 1993 